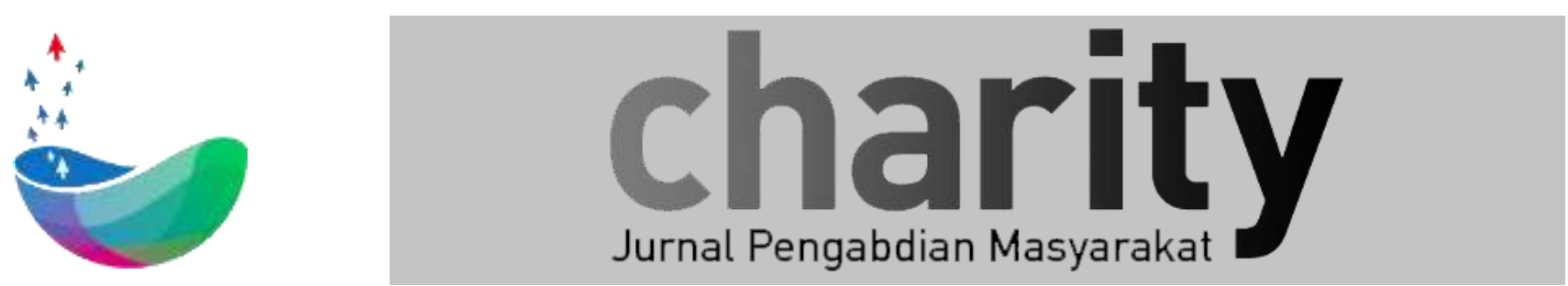

\title{
ARSITEKTUR ENTERPRISE RUMAH PINTAR DESA WARGA SALUYU KECAMATAN GUNUNG HALU
}

\author{
Ririn Dwi Agustin ${ }^{11}$, Fery Mulyanto ${ }^{2}$, R Djunaedi Sakam ${ }^{3}$, Fajar Darmawan ${ }^{4}$ \\ ${ }^{1}$ Universitas Pasundan Bandung \\ *ririn_dwia@unpas.ac.id
}

\section{INFO ARTIKEL}

Diterima 31 Oktober 2017

Direvisi 8 November 2017

Disetujui 16 November 2017

Tersedia Online 24 Oktober 2018
Keyword : Rumah Pintar, Telecenter, Arsitektur enterprise

\begin{abstract}
ABSTRAK
Rumah Pintar Desa Warga Saluyu adalah rumah yang digunakan untuk memintarkan warga desa melalui akses yang lebih luas dan mudah terhadap informasi. Konsep yang diterapkan meniru TELECENTER yang dibangun oleh UNDP bersama BAPENAS dalam program Partnership for e-Prosperity for the Poor di Indonesia pada tahun 2006.

Kepemilikan smartphone masih rendah, jumlah warnet di kecamatan hanya satu, terbatasnya ketrampilan warga tentang cara mengakses informasi, kerentanan warga dalam menyikapi keragaman informasi, kreativitas dari pengurus desa yang baik, ketersediaan sinyal beberapa ISP merupakan alasan yang mendukung kelayakan dibangunnya rumah pintar desa warga saluyu.

Pada arsitektur bisnis, dirancang kegiatan sosial dan kegiatan komersial. Pada kegiatan sosial, layanan akses informasi dirancang berbasis kelompok yang dipimpin oleh mentor untuk kelompok petani, umkm, guru, ibu pkk dan karang taruna. Rancangan ini untuk mengatasi kerentanan warga dalam menyikapi keragaman informasi. Selain akses ada juga layanan upload konten dari warga ke web desa warga saluyu. Untuk mengatasi keterbatasan dana kuota pulsa akses, disediakan model akses online ke internet atau lokal ke PC yang dijadikan server. Di dalam server dikelola pengetahuan yang disiapkan oleh narasumber. Kegiatan komersial adalah pencarian informasi tertentu, layanan cetak dan scan dokumen. Dari arsitektur bisnis ini dirancang arsitektur informasi, aplikasi dan kemudian arsitektur teknologi.
\end{abstract}

Korespondensi :

Direktorat Penelitian dan Pengabdian Masyarakat, Universitas Telkom

Jl. Telekomunikasi No. 1, Terusan Buah Batu, Bandung, 40257

Indonesia.

E-mail: charity@telkomuniversity.ac.id

ORCID ID:

Penulis Pertama: 0000-0003-3038-7106

https://doi.org/10.25124/charity.v1i01.1573

Paper_reg_number Charity0002010102 ( The Authors. Published by Directorate of Research and Community

Service, Telkom University.

This is an open access article under the CC BY-NC 4.0 license (https://creativecommons.org/licenses/by-nc/4.0/) 


\section{PENDAHULUAN}

Desa Warga Saluyu adalah satu dari 9 desa di Kecamatan Gunung Halu Kabupaten Bandung Barat. Terdiri dari 4 dusun dengan total penduduk sekitar 6500 jiwa. Terletak di 8001100 dpl dengan luas kawasan $867 \mathrm{Ha}$, topografi datar dan berbukit. Desa Warga Saluyu memiliki 4 SD/MI yang tersebar di 4 dusun, 1 SMP Negeri dan 1 MTS, serta 10 sekolah PAUD. Pusat pemerintahan desa ada di desa Cibeureum, dimana kantor desa berada di area puncak bukit yang bisa melihat ke seluruh wilayah desa. Profil desa dapat dikunjungi di wargasaluyu.unpas.ac.id.

Dari hasil Dari hasil MMDD (Menggagas Masa Depan Desa), telah dicantumkan setidaknya ada sembilan kondisi yang bisa diperbaiki melalui peningkatan pengetahuan warga sebagai subyek kehidupan di desa Warga Saluyu. Ke sembilan komponen tersebut adalah sebagai berikut :

1. Tidak berjalannya kelompok koperasi simpan pinjam

2. Kurang berjalannya kegiatan kelompok Koperasi

3. Tidak berjalannya kelompok ternak

4. Belum memahami cara bercocok tanam yang baik

5. Sulitnya peningkatan Produksi Home Industri

6. Sulitnya untuk mendapatkan Bibit Unggul Padi bagi kelompok Tani

7. Sering terjadinya penyakit Diare di Musim Hujan Dan Kemarau

8. Belum terlayaninya pelayanan kesehatan bagi Ibu Hamil dan Balita

9. Adanya anak yang masih kekurangan Gizi ( Gizi Buruk )

Dengan topografi yang berbukit dan berlembah, siaran televisi tidak bisa ditangkap dengan mudah dalam kualitas baik. Penduduk harus memiliki perangkat tambahan yang tidak murah. Dari survey terhadap sekitar 70 siswa SMP, dengan bertanya tentang ayah, ibu, kakak, adik, paman/bibi, nenek-kakeknya yang ternyata yang memiliki smartphone hanya sekitar $20 \%$ dan kebanyakan dimiliki oleh kakak atau paman/bibi mereka yang seusia generasi X. Siswa SD dan SMP mayoritas belum memiliki kesempatan cukup untuk mengakses internet. Dari hasil survey di desa tersebut sudah terdapat 1 warnet. Keberadaan sinyal telephone seluler cukup bagus dan banyak pilihan. Namun akan dianalisis ISP mana yang optimal antara harga dan kualitas akses yang tertangkap di dewa Warga Saluyu khususnya di area kantor desa.

Peluang kontribusi informatika untuk mengatasi 9 persoalan dengan kondisi yang ada adalah melalui peningkatan kapasitas warga dengan jalan mendapatkan akses yang lebih luas dan mudah kepada informasi yang relevan dengan persoalan mereka. Dengan semakin pintarnya warga, maka mereka akan mampu mengatasi masalahnya sendiri.

Apa yang terjadi di Desa Warga Saluyu ternyata telah dibahas hingga ke tingkat dunia dengan sebuah isu KESENJANGAN DIGITAL. Kondisi geografis, tingkat pendidikan dan penghasilan masyarakat serta kurangnya pengetahuan akan potensi teknologi informasi dan komunikasi mengakibatkan munculnya permasalahan kesenjangan digital dan kesenjangan informasi. Fakta di lapangan mengindikasikan bahwa tingkat pemahaman dan penerapan teknologi informasi dan komunikasi tidak merata. Beberapa 13ocial telah memanfaatkan dan berkembang dengan baik, tetapi di 13ocial lain belum berkembang terutama di wilayah pedesaan. Hal ini menjadi isu internasional melalui forum Konferensi Tingkat Tinggi Dunia Tentang Masyarakat Informasi (World Summit on The Information Society) yang diprakarsai oleh PBB pada tahun 2003 di Jenewa dan 2005 di Tunisia. Konferensi tingkat dunia ini telah bersepakat menetapkan berbagai program unggulan yang diawali dengan penyediaan infrastruktur telekomunikasi dan internet untuk menghubungkan desa-desa hingga upaya untuk mewujudkan separuh penduduk dunia melek teknologi informasi dan komunikasi sehingga mampu mencerdaskan diri dan memakmurkan kehidupan masyarakat serta bangsa.

Telah disadari bahwa penyediaan akses terhadap TIK saja tidak cukup. Banyak program sejenis lain yang gagal karena mengasumsikan bahwa akses terhadap infrastruktur TIK akan serta merta membuat masyarakat setempat memanfaatkannya. Tahun 2003 UNDP bersama BAPPENAS melakukan penelitian tentang pemanfaatan teknologi informasi dan komunikasi 
untuk pembangunan 14ocial dan ekonomi di Indonesia dengan nama Asia Pacifik Development Information Programme (APDIP). Tahun 2004 penelitian yang sama dilanjutkan dengan nama Prepatory Assistance for ICTs for Human Development. P enelitian ini merekomendasikan berbagai strategi dan Proyek Partnership for e-Prosperity for the Poor $(P e-P P)$. Implementasi proyek Pe-PP adalah bentuk percontohan Multipurpose Community Development Telecenter yang selanjutnya disebut dengan nama Telecenter di enam Provinsi di Indonesia termasuk di Provinsi Jawa Timur. Sejak tahun 2005 hingga sekarang di Jawa Timur telah memiliki 36 Telecenter yang dibentuk dan dibiayai APBD Provinsi dan Kabupaten/Kota.

Berdasarkan analisis persoalan di desa Warga Saluyu, peluang informasi dalam peningkatan kapasitas masyarakat, dan best practice yang dilakukan BAPPENAS bersama UNDP dengan program Multipurpose Community Development Telecenter maka rumusan persoalan menjadi bisa dikerucutkan sebagai berikut :

1. Bagaimana Arsitektur Bisnis dari rumah pintar untuk desa Warga Saluyu

2. Bagaimana Arsitektur informasi dan arsitektur aplikasi untuk mendukung arsitektur bisnis tersebut

3. Bagaimana Arsitektur Teknologi yang menyediakan infrastruktur untuk rumah pintar tersebut

4. Bagaimana tahapan/roadmap untuk menuju terwujudnya rumah pintar yang hidup dan menghidupkan

Rumusan persoalan ini mengikuti tahapan pengembangan arsitektur enterprise dari TOGAF, dan yang dibahas dibatasi tahap Business Architecture, Information Systems Architecture, Technology Architecture, dan Migration Planning.

\section{METODE PELAKSANAAN PENGABDIAN MASYARAKAT}

Pengabdian masyarakat ini pada praktek di lapangan merupakan gabungan antara metode pemanfaatan teknologi dan metode pendidikan untuk masyarakat. Namun yang akan diuraikan pada tulisan ini adalah aspek rancangan sistem rumah pintarnya. Uraian dilakukan menggunakan metode perancangan arsitektur enterprise.

Arsitektur enterprise adalah kerangka kerja atau cetak biru dari bagaimana organisasi mencapai tujuan bisnis saat ini dan masa dengan dengan cara menguji critical success factor , informasi, aplikasi, dan strategi teknologi dan dampaknya terhadap fungsi bisnis.

Menurut [] arsitektur enterprise terdiri dari tiga layer, yakni arsitektur bisnis, arsitektur sistem informasi, dan arsitektur teknologi .

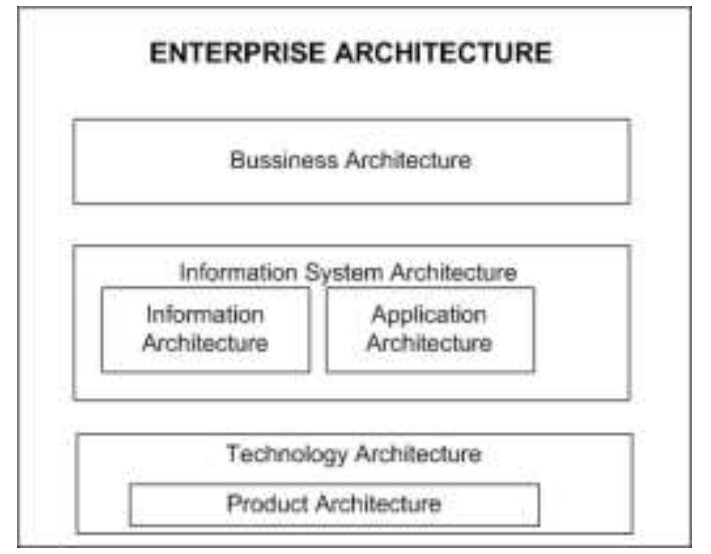

Gambar 1 Komponen Enterprise Architecture

Tahapan pengembangan arsitektur enterprise (ADM) menurut TOGAF ada 8 tahap, yakni Tahap A : Architecture Vision, 
Tahap ini bertujuan untuk menyusun maksud dan tujuan dibuatnya EA termasuk didalamnya ruang lingkup, kebijakan, harapan, masalah yang akan dipecahkan, bentuk output yang diinginkan. Output dari fase ini disebut dengan dokumen statement of architecture work.

Phase B: Business Architecture,

Tahap ini mengidentifikasi baseline dan target serta mencari celah (gap) antara keduanya untuk memperbaharui kebutuhan bisnis yang telah dibuat pada fase A.

Phase C: Information Systems Architecture,

tahap ini menyusun sistem yang telah ada dibandingkan dengan kebutuhan sistem. Pada tahap ini disusun arsitektur data dan arsitektur informasi yang menjadi dasar dari terbentuknya sistem informasi.

Phase D: Technology Architecture,

teknologi akan menjadi dasar implementasi sistem informasi dan seluruh aliran data pada lingkup arsitektur sistem informasi yang dibangun.

Phase E: Opportunities and Solution,

Tahap ini mengidentifikasi peluang-peluang bisnis yang muncul setelah semua arsitektur teridentifikasi dan memberikan solusi atas peluang-peluang tersebut untuk mencapai sasaran dari arsitektur yang telah dibangun.

Phase F: Migration Planning,

Tahap ini menyusun roadmap dari tahap implementasi, menyusun prioritas dari integrasi proyek-proyek agar berjalan sesuai dengan rancangan arsitektur.

Phase G: Implementation Governance, melaksanakan tatakelola dari arsitektur yang dibuat, termasuk menyusun tim, membuat manajemen proyek dan kontrol.

Phase H: Architecture Change Management, karakteristik manajemen lebih cepat berubah dari perkembangan teknologi, oleh karenanya manajemen perlu mengatur teknologi agar bisa sejalan dengan tujuan organisasi. Output tahap ini adalah perubahan arsitektur manajemen yang mendukung arsitektur yang telah dibuat setelah melalui tahap implementasi.

\section{ANALISA HASIL KEGIATAN PENGABDIAN MASYARAKAT}

\subsection{Arsitektur Bisnis}

Konsumen langsung dari rumah pintar desa warga saluyu adalah kelompok masyarakat desa warga saluyu yang tergabung berdasarkan isu atau kepentingan yang sama. Yang dimaksud dengan isu tersebut dibatasi sebagai berikut

1. Siswa SMP

2. Siswa SD

3. Kelompok Tani

4. Kelompok Usaha Kecil

5. Kelompok Ibu PKK

6. Kelompok Guru SD/PAUD

Kelompok masyarakat tersebut memiliki kepentingan untuk mendapatkan informasi dan memperbincangkannya untuk kemudian bisa diambil tindakan praktis yang implementatif sesuai dengan konteks dalam kehidupan masyarakt desa warga saluyu. Tindakan praktis tersebut kemudian dipraktekkan dan didiskusikan kendala serta hasilnya. Dari kendala maka akan memicu kebutuhan informasi baru dari dunia maya untuk mendapatkan solusi. Sedangkan dari hasil akan muncul kepentingan yang kedua yakni kewajiban moral untuk berbagi kepada dunia tentang kisah/cerita/pengalaman menarik di kehidupan warga.

Karena di desa Warga Saluyu ada cukup banyak sekolah maka biasanya siswa sekolah mendapatkan tugas untuk mencari informasi tertentu di internet. Atau ada pula warga yang memiliki kepentingan untuk mengirimkan email kepada keluarganya yang merantau keluar desa. Di era digital mungkin ada juga warga yang membutuhkan jasa digitalisasi dengan scanner, misal dokumen resmi untuk melamar pekerjaan. Kelompok masyarakat ini akan menjadi konsumen layanan komersial dari rumah pintar. 
Layanan yang disediakan Rumah Pintar Desa Warga Saluyu dibagi menjadi dua macam, yakni layanan sosial dan layanan komersial . Layanan sosial terdiri dari

a. Layanan akses informasi secara berkelompok yang masing-masing menggunakan tablet. Akses informasi yang diharapkan adalah online secara real time ke dunia maya. Disediakan pula akses ke servel lokal sebagai backup jika koneksi ke dunia maya terganggu baik karena teknis jaringan maupun karena kuota pulsa yang habis.

b. Layanan nonton bersama dan diskusi. Juga dilakukan secara berkelompok namun hanya mentornya yang melakukan akses informasi ke dunia maya, sedangkan anggota kelompok lainnya menyimak tayangan, gambar, suara, atau tulisan yang dipilih untuk ditayangkan mentor.

c. Layanan upload konten. Dewa warga saluyu sudah memiliki website. Pada website disediakan halaman berita. Warga dengan ijin mentornya dapat memposting gambar, tulisan, atau video ke website desa. Proses upload dilakukan oleh operator, sedangkan warga cukup menyerahkan konten tersebut ke operator rumah pintar.

Layanan komersial diantaranya adalah

1. Kirim dan Buka Email

2. Cari dan Cetak Informasi dari internet

3. Digitalisasi Dokumen/Gambar

4. Edit Video/Gambar

Proses bisnis yang dirancang untuk menghasilkan layanan tersebut dapat dikategorikan menjadi layer teknis dan layer bisnis.

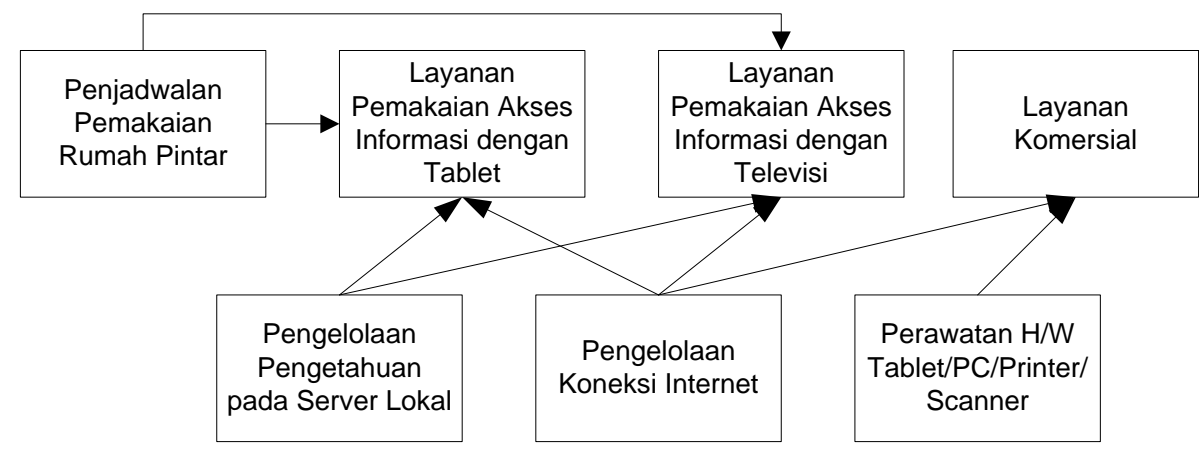

gambar 2 Proses Bisnis Rumah Pintar Desa Warga Saluyu

Layer teknis meliputi proses untuk

1. pengelolaan pengetahuan

2. Pengelolaan koneksi internet

3. Perawatan $\mathrm{H} / \mathrm{W}$ dan perpheral

Layer bisnis meliputi proses :

1. Pendaftaran dan Penjadwalan pemakaian rumah pintar

2. Layanan akses informasi menggunakan tablet

3. Layanan akses informasi menggunakan televisi

4. Layanan komersial

Gambar 3 mendeskripsikan alur dari proses bisnis pendaftaran dan penjadwalan serta layanan akses informasi baik menggunakan tablet maupun menggunakan televisi.

Aktor bisnis pada sistem rumah pintar terdiri dari operator, pengelola konten, mentor.

1. Operator adalah seorang yang memiliki kemampuan menggunakan IT dengan baik sekaligus kemampuan komunikasi interpersonal yang bagus. Tugasnya menjadi motor utama dalam menjalankan proses pada layer bisnis. Hadir dan siap berada di rumah pintar setiap hari pada jam kerja. 
2. Teknisi adalah seorang yang memahami jaringan komputer dan hardware. Tugasnya adalah mengelola koneksi internet dan merawat hardware serta peripheral serta membantu pengelola pengetahuan untuk memasukkan konten baru ke server lokal. Teknisi bekerja satu minggu sekali dan on-call jika ada problem teknis yang dilaporkan oleh operator. Saat ini teknisi masih diperankan oleh dosen Teknik Informatika Unpas.

3. Pengelola Pengetahuan adalah narasumber dari dosen teknik Informatika Unpas. Perannya adalah mencarikan link internet untuk mendapatkan konten yang relevan dengan konteks kelompok masyarakat. Selain itu juga mendownload konten yang dipilih untuk di simpan di server lokal. Secara periodik, bahan pengetahuan diserver lokal ditambah atau diupdate.

4. Mentor memiliki peran yang sangat penting dalam suksesnya sebuah rumah pintar. Mentor adalah seorang yang cukup menjadi publik figur, memiliki pengetahuan yang luas, kemauan dan kemampuan untuk belajar mandiri dari internet, memiliki kemampuan komunikasi interpersonal dan leadership yang baik. Mentor terdiri dari beberapa orang, sesuai dengan konteks pengetahuannya

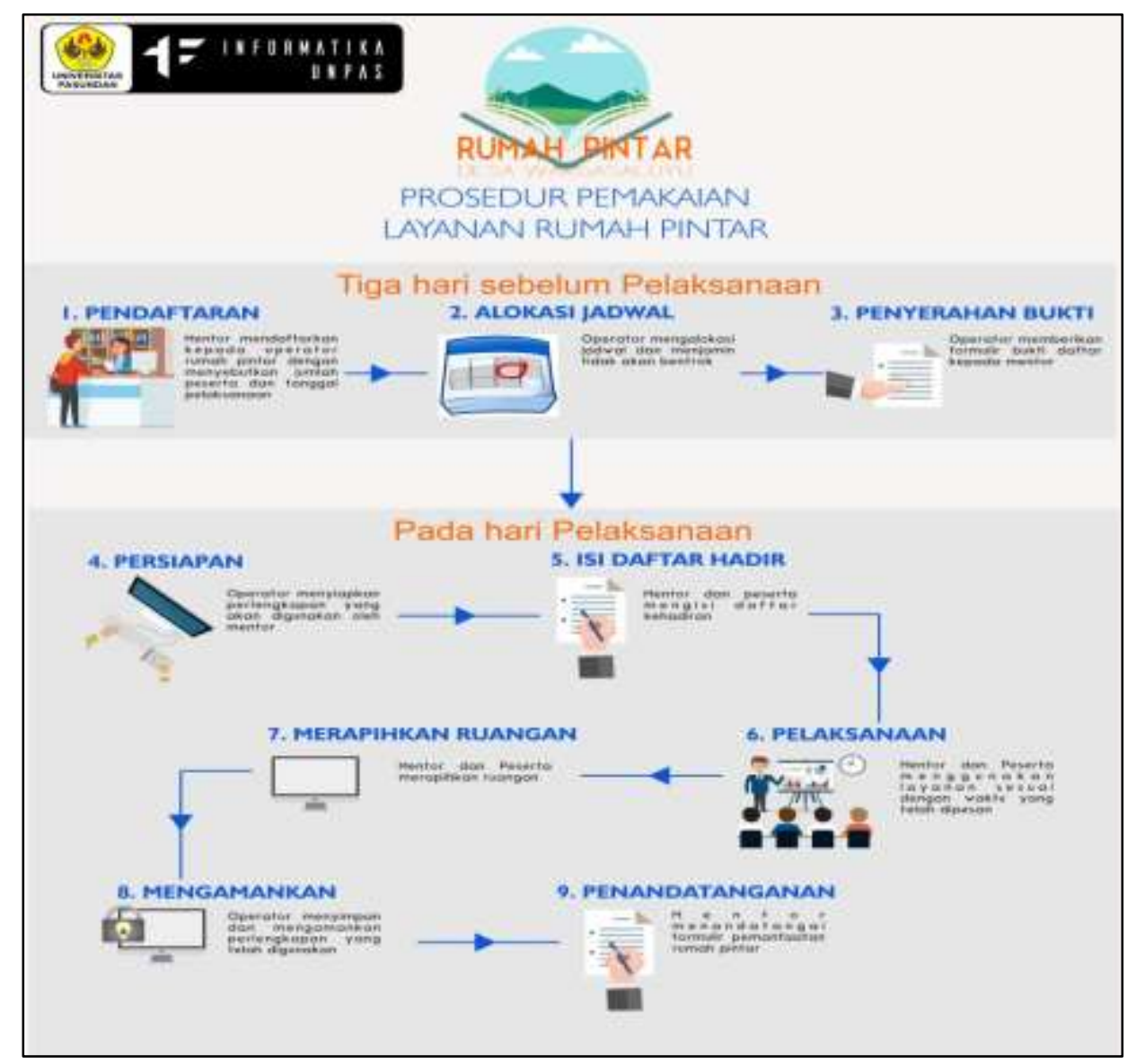

gambar 3 Prosedur dalam Proses Bisnis Pendaftaran dan Layanan Akses Informasi 3.2 Arsitektur Sistem Informasi

Informasi yang dibutuhkan oleh konsumen rumah pintar sebenarnya terbuka apapun yang ada di dunia maya. Namun untuk lebih mengefektifkan manfaat dari lautan informasi yang ada, maka ragam informasinya dibatasi dengan konteks

1. Pengkayaan metode pembelajaran dan bahan ajar untuk PAUD, SD, SMP

2. Pertanian

3. Industri UMKM

4. Pemberdayaan Perempuan

Tidak ada aplikasi khusus yang perlu dibangun dalam sistem rumah pintar ini. Aplikasi massal yang digunakan meliputi browser, editor gambar dan video, microsoft Office 


\subsection{Arsitektur Teknologi}

Teknologi informasi yang digunakan pada sistem rumah pintar pada dasarnya hanya teknologi internet. Untuk menyesuaikan dengan kebutuhan arsitektur bisnis maka perangkat IT dan keterkaitan antar perangkat dirancang sebagaimana pada gambar

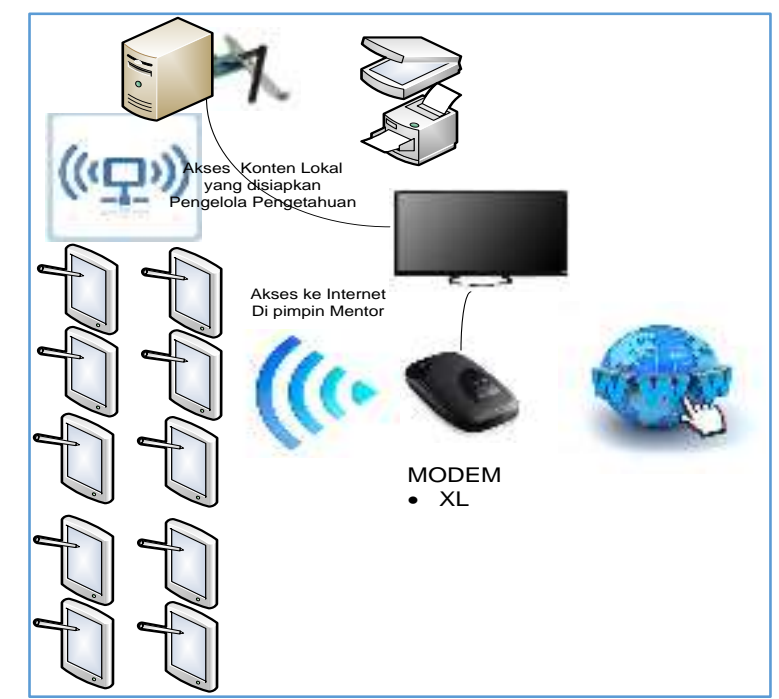

gambar 4 Arsitektur Teknologi untuk Mendukung Rumah Pintar

Layanan penyedia internet yang tersedia di Desa Gunung halu pada saat dilakukan pengecekan yaitu menggunakan penyedia layanan internet dari operator selular XL. Berdasarkan data yang kami dapatkan dari website XL untuk cakupan internet jaringan 4G di lokasi Desa Gunung Halu, sudah hampir sebagian besar tercover. Gambar 5 mendeskripsikan coverage area dari XL. Pengamatan dilakukan di koordinat

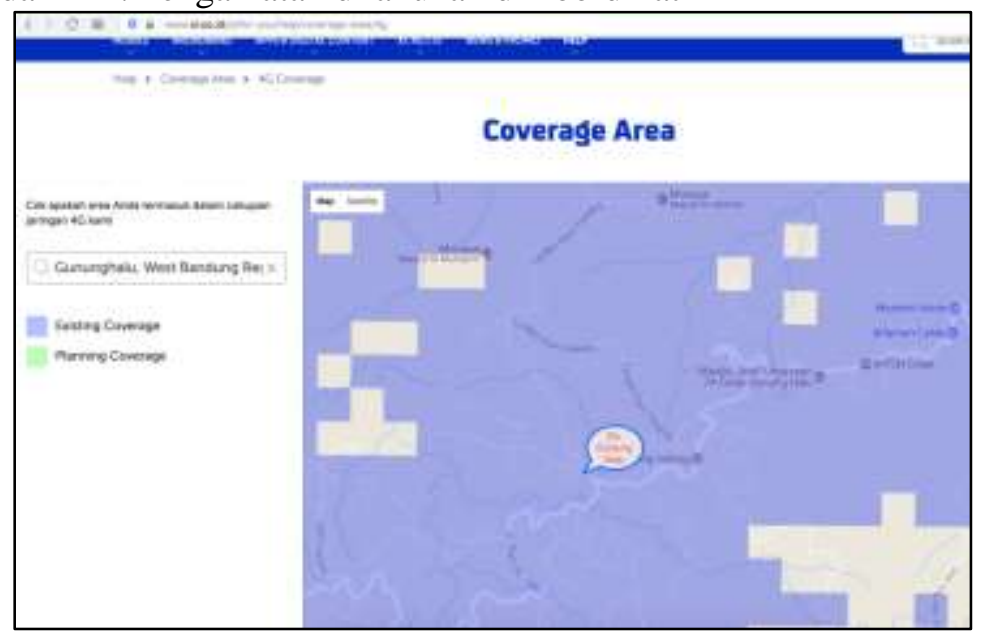

gambar 5 Pengecekan Koneksi Internet untuk Rumah Pintar

Koordinat titik pengukuran berada di Kantor Desa Gunung halu yang berlokasi di : Latitude : -7.014073, dan Longitude : 107.338901, menggunakan speedtest.net. Hasilnya adalah sebagai berikut:

Nama ISP

Lokasi Tes

Besaran Latency (Ping time)

Besaran Bandwith Download

Besaran Bandwith Upload
: Excelcomindo

: Kantor Desa Gunung Halu

: $25 \mathrm{~ms}$

: $16.71 \mathrm{Mbps}$

: $3.16 \mathrm{Mbps}$ 


\begin{tabular}{|l|l|l|l|}
\hline \multicolumn{1}{|c|}{ Jenis Test } & \multicolumn{1}{c|}{ Hasil Pengukuran } & \multicolumn{1}{c|}{ Indeks } & \multicolumn{1}{c|}{ Kategori } \\
\hline Latency Test & $25 \mathrm{~ms}$ & Sangat Bagus & 4 \\
\hline Throughput Test (Download) & $16.71 \mathrm{Mbps}$ & Terbaik & 4 \\
\hline Throughput Test (Upload) & $3.16 \mathrm{Mbps}$ & Terbaik & 4 \\
\hline
\end{tabular}

Selain teknologi informasi, Rumah Pintar Desa Warga Saluyu juga membutuhkan ruangan. Ruangan yang dibutuhkan terdiri dari dua, yakni bilik akses internet melalui tablet dan ruang nonton bersama yang digabung dengan ruang opetrator. PC server, scanner, dan printer serta televisi disimpan di ruang nonton bersama . Ruang ini dilengkapi dengan kursi. Dalam bilik akses internet disimpan rak kaca untuk menyimpan tablet dan karpet serta papan tulis untuk akses informasi bersama menggunakan tablet. Kebutuhan ini dirumuskan setelah disesuaikan dengan ketersediaan ruangan yang disediakan oleh Desa

\subsection{ROADMAP IMPLEMENTASI}

Ada empat aspek yang dibutuhkan untuk mewujudkan rumah pintar desa warga saluyu hingga mulai beroperasi, yakni

a) infrastruktur, terdiri dari fisik dan teknologi informasi .,

b) SDM,

c) Pengetahuan

d) program kerja 3 bulan

Berdasarkan rencana waktu pelaksanaan PPM adalah 9 bulan, maka tahapan mewujudkan rumah pintar dirancang sebagai berikut

\begin{tabular}{|c|c|c|c|c|c|c|c|c|c|c|c|}
\hline \multirow[b]{2}{*}{ No } & \multirow[b]{2}{*}{ Kegiatan } & \multirow[b]{2}{*}{ Output } & \multicolumn{9}{|c|}{ Waktu Pelaksanaan } \\
\hline & & & Mar & Apr & Mei & Jun & Jul & Agu & Sept & Okt & Nov \\
\hline 1 & Requirement Gathering & $\begin{array}{l}\text { Kegiatan dihadiri oleh sedikitnya } 2 \text { warga, pejabat } \\
\text { desa, ketua karang taruna, ketua PKK, dewan masjid, } \\
\text { ketua pembina UMKM desa }\end{array}$ & & & & & & & & & \\
\hline & $\begin{array}{l}\text { Sosialisasi dan Tim Building } \\
\text { Rumah Pintar }\end{array}$ & Terdefinisinya kandidat manajer, operator, mentor & & & & & & & & & \\
\hline 3 & $\begin{array}{l}\text { Penyiapan Pengetahuan dan } \\
\text { Penyusunan Modul Mentoring }\end{array}$ & Modul Mentoring untuk setiap komunitas & & & & & & & & & \\
\hline & & daftar Link Internet yang relevan dengan komunitas & & & & & & & & & \\
\hline & & Kumpulan film, ebook yang relevan dengan komunitas & & & & & & & & & \\
\hline 4 & Tim Bulding Mentor & \begin{tabular}{|l|l}
$\begin{array}{l}\text { Mentor memahami modul dan bisa praktek sebagai } \\
\text { mentor }\end{array}$ \\
\end{tabular} & & & & & & & & & \\
\hline 5 & $\begin{array}{l}\text { Penyiapan Ruangan dan } \\
\text { Furniture }\end{array}$ & Ruangan Rumah Pintar & & & & & & & & & \\
\hline 6 & Pengadaan Peralatan TI & Tablet & & & & & & & & & \\
\hline & & PC\& monitor, Printer, Scanner siap & & & & & & & & & \\
\hline 7 & $\begin{array}{l}\text { Instalasi Ruangan dan peralatan } \\
\mathrm{TI}\end{array}$ & Peralatan TI Siap dipakai & & & & & & & & & \\
\hline 8 & Launching & Terlaksananya kegiatan & & & & & & & & & \\
\hline & & Jumlah warga yang hadir & & & & & & & & & \\
\hline 9 & $\begin{array}{l}\text { Pendampingan program selama } \\
3 \text { bulan }\end{array}$ & Jadwal Penggunaan Rumah Pintar oleh Komunitas & & & & & & & & & \\
\hline & & Pelaksanaan Mentoring komunitas oleh mentor & & & & & & & & & \\
\hline
\end{tabular}

\section{PEMBAHASAN}

Pada subbab ini akan diuraikan mengenai hasil dari pelaksanaan roadmap serta capaian indikator output serta kendala dan dukungan positif yang didapat dari warga Desa Warga Saluyu.

Secara umum kegiatan terlaksana dengan baik, hanya saja waktunya terlambat dari yang direncanakan, sehingga pada bulan november baru bisa dilaksanakan launching. Pemerintah Desa Warga Saluyu menyambut dengan baik program pembangunan rumah pintar dengan 
bukti telah menyiapkan ruangan yang sangat memadai dan bagus serta mengintegrasikan rumah pintar ini dengan perpustakaan desa dalam pelaksanaan program "Bunda Literasi".

Keterlibatan warga cukup bagus, meskipun masih sebatas pada kader-kader desa yang diharapkan perannya sebagai mentor, operator, dan tokoh komunitas. Antusias para kader pada ketegori baik, dan mereka terlihat patuh pada arahan dari Pimpinan Desa.

Komitmen dari Kampus juga sangat dengan ditunjukkannya dukungan dana untuk pengadaan peralatan dan komitmen dari para pelaksana PPM yang tinggi sehingga kegiatan penyiapan maupun interaksi dengan warga dapat terlaksana.

Kendala yang dihadapi adalah bahwa jumlah mentor yang diharapkan sebanyak 10 orang masing-masing untuk setiap komunitas dari lima komunitas yang ditargetkan tidak berhasil. Dari kegiatan terakhir diperkirakan kandidat mentor yang diperkirakan siap untuk menjadi dinamisator rumah pintar ada 8 orang.

Ada diantara kader yang sudah berpikir ke depan tentang keberlanjutan rumah pintar setelah launching. Sebelum program 3 bulan disodorkan oleh Tim, Pimpinan Desa beserta kader telah lebih dulu memiliki inisiatif untuk masa perdana 3 bulan akan mengundang setiap sekolah menggunakan rumah pintar sebagai wahana belajar di luar ruang kelas. Antuasiasme kedua selain pemakaian rumah pintar untuk guru dan siswa adalah pada komunitas ibu-ibu PKK. Hal ini dilihat dari kehadiran tim mentor komunitas selama proses tim building mentor yang dilakukan sebanyak 4 kali pertemuan.

Harapan berjalannya program kerja layanan sosial tidak diragukan dengan adanya banyak sekolah di desa warga saluyu. Program layanan bisnis belum bisa digulirkan diawal berdasarkan saran dari pimpinan Desa. Dana operasional desa akan digilirkan untuk honor operator dan biaya pulsa. Ke depan jika manfaatnya sudah bisa dirasakan masyarakat maka program layanan bisnis baru diperkenalkan.

Secara teknis terdapat tantangan yang baru ditemukan yakni pengamanan akses internet tentang bagaimana agar kuota internet tidak bisa diambil secara bebas oleh warga. Hal ini bisa diatasi dengan mengupgrade MODEM ke spesifikasi yang manageable sehingga modem hanya bisa diakses oleh tablet dengan mac adress yang didaftarkan. Modem bisa dipantau jarak jauh, sehingga selama pendampingan bisa dimonitor dari kampus.

\section{SIMPULAN DAN SARAN}

Dari uraian rumusan masalah, analisis hasil hingga pembahasan dapat disimpulkan beberapa hal

1. Aspek Infrastruktur dari Rumah Pintar sudah tersiapkan dengan sangat baik dan diperkirakan tidak ada kendala

2. Dari aspek SDM, ada sedikit kendala dari segi jumlah mentor namun dipekirakan dari jumlah yang ada bisa menjadi dinamisator pengembangan ke depan.

3. Dari aspek program kerja, terdapat layanan bisnis dan layanan sosial. Yang bisa digulirkan saat ini baru layanan sosial.

4. Dari aspek pengetahuan, belum bisa dilakukan pengujian kesesuaian antara konten-konten yang disimpan dalam server lokal dengan kebutuhan dan ketertarikan calon pengguna rumah pintar.

\section{DAFTAR PUSTAKA}

[PER,04] Pereira, C. M. \& Sousa, P., 2004. A Method to Define an Enterprise Architecture Using the Zachman Framework. Proceeding at the ACM Symposium on Applied Computing 2004, pp. 1366-1371.

[MOC,07] Zulfikar Mochamad MBUKU 4 - Panduan untuk Fasilitator Infomobilisasi Teknik Fasiltiasi Partisipatif Pendampingan Masyarakat, PANDUAN UNTUK FASILITATOR / pengar. Zulfikar Mochamad Rachman Rianingsih Djohani, Dwi Joko Widyanto, Riza Irfani. - Jakarta : Tim Partnerships for e-Prosperity for the Poor (Pe-PP) BAPENAS-UNDP, 2007.

[Bap,07] Buku Acuan Pendirian, Pengembangan, dan Pengelolaan Telecenter [Buku] / pengar. Penulis Tim. - Jakarta : Tim Partnership Pe- PP Bappenas-UNDP , 2007. 
[Har,05] Model dan Arsitektur Sistem dan Teknologi Informasi untuk Sektor Publik, TEKNOMATIKA Vol. 7, No. 2, JANUARI 2015 , ISSN: 1979-7656, page 43-56

\section{FOTO KEGIATAN \& VIDEO SINGKAT}
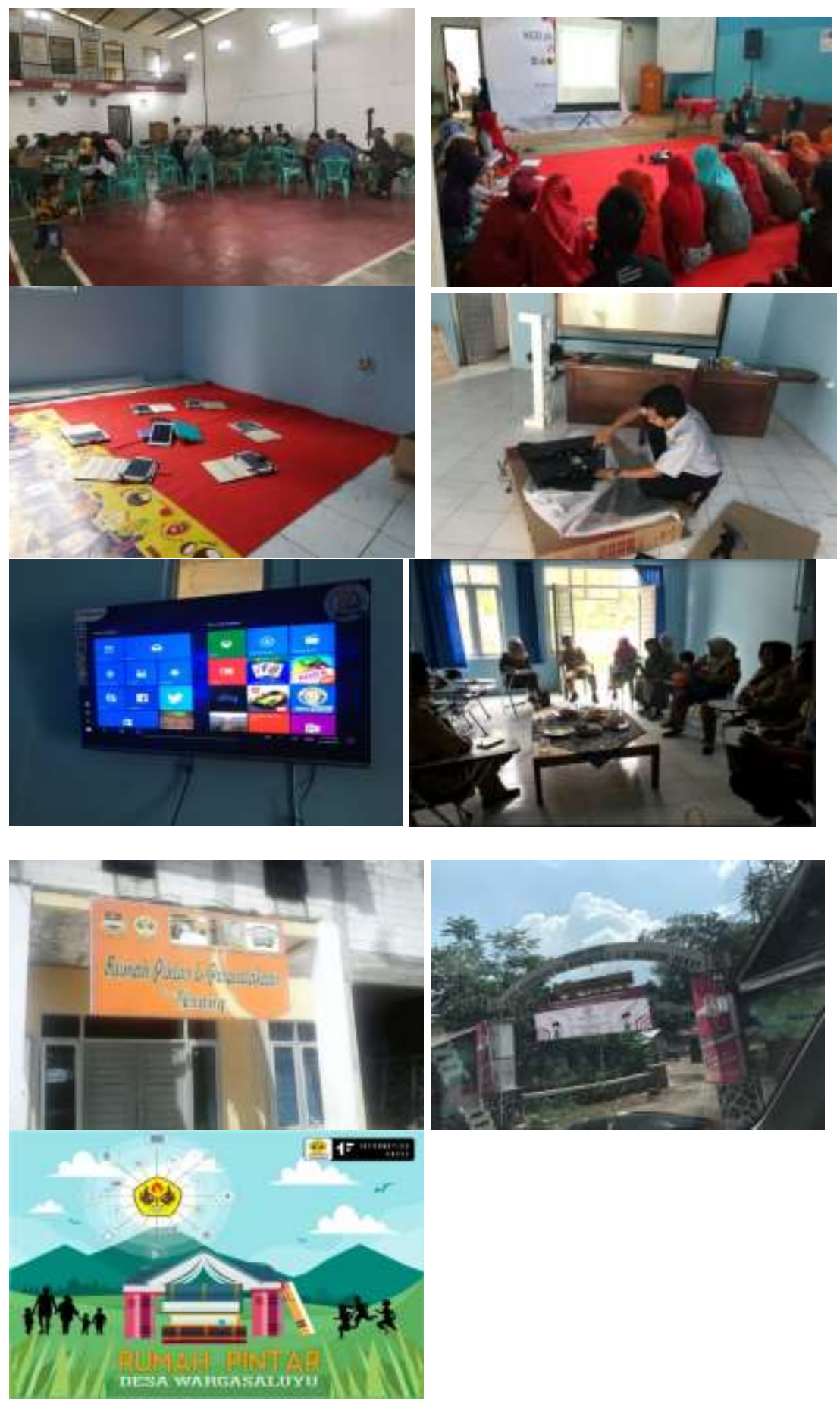


\section{IDENTITAS PENULIS (BIODATA BERUPA NARASI SINGKAT) \\ Ririn Dwi Agustin}

Adalah dosen tetap di Teknik Informatika Universitas Pasundan. Saat ini menjabat sebagai wakil dekan I Fakultas Teknik. Lahir di kota kediri Jawa Timur, pada tahun 1971, pendidikan sarjana hingga doktoral ditempuh di Informatika STEI-ITB. Lulus Doktor pada awal tahun 2016. Kepakarannya di bidang Tata Kelola TIK, Sistem Cerdas,dan Serious Game Fery Mulyanto

Adalah dosen tetap di Teknik Informatika Unpas, saat ini menjabat sebagai Divisi Infrastruktur di SPTIK UNPAS. Alumni IF Unpas tahun 2003 ini menyelesaikan magisternya di Universitas AKAKOM Yogyakarta kerjasama dengan program PJJ APTIKOM. Kepakarannya internet marketing dan network engineering

\section{Rawan Djunaedi Sakam}

Adalah dosen tetap di Teknik Informatika UNPAS. Menyelesaikan magisternya di Sistem Informasi STEI-ITB. Kepakarannya pada bidang kewiraausahaan dan sistem informasi

Fajar Darmawan

Adalah dosen tetap di Teknik Informatika Unpas. Alumni IF Unpas tahun 2003 ini menyelesaikan magisternya di Universitas AKAKOM Yogyakarta kerjasama dengan program PJJ APTIKOM. Kepakarannya Pemrograman Mobile dan Multimedia 